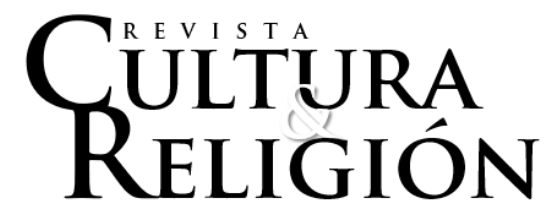

Vol. XV, $\mathrm{N}^{\circ} 1$ (2021) pp. 223-258

Recibido: 17 de junio, 2020

Aceptado: 9 de mayo, 2021

\title{
COMUNICAÇÃO E CULTURA NAS COMUNIDADES ECLESIAIS DE BASE (CEBs): UM ESTUDO DE CASO NO CENTRO-OESTE DO BRASIL
}

Communication and culture in basic ecclesial communities (BECs): a case study in the central-western region of Brazil

Gibran Luis Lachowski*

Universidade Federal de Mato Grosso

(UFMT)

ORCID: 0000-0002-6649-1020

\author{
Yuji Gushiken** \\ Universidade Federal de Mato Grosso (UFMT) \\ ORCID: 0000-0002-6620-3375
}

\section{Resumo}

Este artigo objetiva investigar a dimensão comunicacional das práticas culturais das Comunidades Eclesiais de Base (CEBs), vinculadas à Igreja Católica. A pesquisa, de caráter qualitativo, baseia-se em estudo de caso, via observação participante, referente a um encontro sobre o tema Juventude e Bem Viver, realizado em maio de 2019 na cidade de Cuiabá, capital de Mato Grosso, Centro-Oeste do Brasil. A abordagem teórica se orienta pelo modelo de estudos da comunicação como cultura, tendo por marcos interdisciplinares comunicação como "ciência do comum" e como "diálogo" e cultura enquanto "ciência interpretativa". O artigo traz arcabouço conceitual e composição histórica das CEBs - desde a luta contra a ditadura no Brasil nos anos 1960 -, destaca suas parcerias sociopolíticas e viabilização de pautas prioritárias. Descreve o funcionamento atual das CEBs a partir de práticas culturais produtoras de 
sentido e de valor simbólico. As conclusões apontam para uma indiscernibilidade entre comunicação e cultura, na medida em que as CEBs: constituem um modo de ser pela convergência dos campos racional, lúdico, artístico, afetivo e espiritual; operam formas organizativas pautadas por múltiplos tipos de cooperação; e desenvolvem uma capacidade plástica de diálogo com entes religiosos e da sociedade em geral.

Palavras-chave: Cultura, Comunicação, CEBs, Bem Viver, Brasil.

\begin{abstract}
This article aims to investigate the communicational dimension of the cultural practices of the Basic Ecclesial Communities (BECs), linked to the Catholic Church. The research, which was of a qualitative nature, is based on a case study through participant observation, referring to a meeting in May 2019 on the theme of Youth and Good Living, held in the city of Cuiabá, the capital of the state of Mato Grosso, in the central-western region of Brazil. The theoretical approach is guided by the model of studies of communication as culture, with interdisciplinary references such as communication as "science of the common" and as "dialogue" and culture as "interpretive science". The article brings the conceptual framework and the historical composition of the BECs - since the struggle against the dictatorship in Brazil in the 1960s -, and highlights their socio-political partnerships and the viability of priority guidelines. It describes the current functioning of BECs based on cultural practices that produce meaning and symbolic value. The conclusions point to an indiscernibility between communication and culture, insofar as the BECs: constitute a way of being through the convergence of the rational, ludic, artistic, affective and spiritual fields; they promote organizational forms guided by multiple types of cooperation; and develop an articulated capacity for dialogue with religious entities and society in general.
\end{abstract}

Keywords: Culture, Communication, BECs, Good Living, Brazil. 


\section{Introdução}

As Comunidades Eclesiais de Base (CEBs) da Igreja Católica constituem-se num conjunto de experiências latino-americanas registradas, ao menos, desde a década de 1960, gestadas no Brasil a partir do contexto de luta contra a ditadura militar e dos ventos progressistas do Concílio Vaticano II. De modo geral, as CEBs são caracterizadas pela religiosidade popular, orientação contestatória da Teologia da Libertação (TdL) e protagonismo do laicato (fiéis leigos, que não pertencem ao clero) dentro da esfera eclesial e na sociedade como um todo. Tais nomenclaturas e episódios serão detalhados no decorrer do artigo.

As CEBs foram fundamentais na criação de importantes organizações sociais no Brasil, como a Comissão Pastoral da Terra (CPT), o Conselho Indigenista Missionário (CIMI), o Movimento dos Trabalhadores Rurais Sem Terra (MST), e também contribuíram para a retomada do novo sindicalismo brasileiro nos anos 1970/1980.

Da década de 1990 para cá, as CEBs passaram por outro momento, em razão da globalização econômica e do ritmo intensificado de urbanização e industrialização no Brasil, além dos conflitos eclesiais durante os papados considerados conservadores de João Paulo II (1978-2005) e Bento XVI (20052013), mais voltados à doutrina da fé que ao protagonismo dos leigos na Igreja e na sociedade.

Esse cenário propiciou o direcionamento da ação e das experiências das CEBs para os centros urbanos, onde possuem menor presença, e tornou premente a construção de um projeto de sociedade que, mais do que oposto ao capitalismo, se dê para além do desenvolvimentismo que também suporta a noção de progresso em parte dos países socialistas e comunistas, constituindose e reatualizando uma utopia denominada de "Reino de Deus na Terra".

A revisão bibliográfica em curso (Marins, 2015; Orofino, Coutinho, \& Rodrigues, 2012; Menezes, 2010; Barbosa, 2008; Alves, 2008; Santos, 2006) mostra que estudos e pesquisas sobre as CEBs concentram-se nas áreas das 
Ciências da Religião, Sociologia, Antropologia, Teologia, Educação e História. Sendo assim, uma investigação científica a partir da Comunicação, na interface com a Cultura, como a que se expõe neste artigo, amplia o leque de abordagens, ao mesmo tempo em que abre espaço a um campo de conhecimento pouco mencionado quanto ao referido objeto de pesquisa.

\section{Trajeto teórico-metodológico da pesquisa}

Este trabalho de pesquisa situa-se no rol de estudos mais recentes sobre o catolicismo, a religiosidade popular e as questões sociais na América Latina, o que inclui investigações de autores como Granados Valdéz (2020), Leonardi (2020), Garcés (2019), Ros Codoñer (2018) e Delgado Molina (2108).

Este artigo orienta-se pelo modelo teórico de estudos da "comunicação como cultura" e, também, pela angulação da "comunicação como diálogo". São postulações para além dos paradigmas liberal clássico e marxista instrumental, e integram mapeamento epistemológico do comunicólogo brasileiro Venício Artur de Lima (2001).

Neste modelo, contribui a abordagem da "ciência do comum", do jornalista, sociólogo e estudioso das áreas de Comunicação e Cultura, Muniz Sodré (2014). A tese de Sodré baseia-se na vinculação social em dimensão interpessoal, num processo em que "o comum” é antes sentido do que pensado; portanto, mais amplo do que o linguístico (pois considera o extralinguístico).

Trata-se de uma pesquisa de caráter qualitativo, com base em revisão bibliográfica que permitiu compreender a dimensão histórica das CEBs. Adotase um estudo de caso, via observação participante e pesquisa de campo. Buscase, portanto, o significado da realidade humana vivida socialmente (Minayo, 2002), auxiliada por um processo descritivo dos dados levantados e trabalho de interpretação. O trabalho de campo referiu-se a um encontro de CEBs com o tema “Juventude e Bem Viver", realizado em Cuiabá, capital do estado de Mato Grosso, região Centro-Oeste do Brasil, em maio de 2019. 
O estudo de caso foi a opção utilizada para aproximar-se da realidade empírica do objeto de pesquisa e trilhar o caminho da busca do significado cerne da investigação qualitativa. Afinal, o trabalho de campo traduz-se num "momento relacional e prático de fundamental importância exploratória, de confirmação ou refutação de hipóteses e construção de teorias", conforme enuncia a socióloga e antropóloga Maria Cecília de Souza Minayo (2002, p. 26).

Os dados levantados foram ordenados quanto às entidades participantes, às relações conceituais que o tema do encontro possibilitou e às práticas culturais percebidas. Registraram-se várias categorias de informação no que tange ao evento estudado; todavia, as mencionadas acima correspondem às mais expressivas no processo de imbricamento entre comunicação e cultura. Evidenciam elementos característicos das postulações teóricas expostas por Lima (2001), associadas a um pensamento latino-americano centrado em práticas comunicacionais dialógicas (Gushiken, 2006).

Entre essas práticas dialógicas estão: o compartilhamento de sentidos (em vez do caráter transmissivo da comunicação); a valorização das relações cotidianas (e não a perspectiva utilitarista); a proatividade dos sujeitos envolvidos (por serem construtores de mediações culturais); e o processo educativo problematizador (em contrapartida ao padrão bancário, em que o professor se considera detentor do saber).

Mais detidamente, o modelo teórico da comunicação enquanto cultura mostra a

[...] comunicação definida com significação oposta ao polo da transmissão, isto é, como compartilhamento, como cultura. Em contraposição aos modelos behavioristas, busca-se a compreensão (e não a formulação de leis) das representações e práticas culturais que expressam os valores e significados construídos na relação entre a mídia e as demais instituições da sociedade urbana contemporânea. (Lima, 2001, p. 49-50) 
Enquanto isso, o modelo da comunicação como diálogo, elaborado pelo pedagogo Paulo Freire ainda nos anos 1960, ganhou aplicabilidade junto às mídias na medida em que as tecnologias se tornaram mais acessíveis e os setores populares se apropriaram delas para potencializar suas visões de mundo, rompendo com o caráter unilateral anterior. Assim, a antiga proposição "passou a servir de ideal para a realização plena da comunicação humana, em todos os seus níveis" (Lima, 2001, p. 51).

Não se restringindo ao plano midiático, esse modelo teórico, como explica o autor, é capaz de captar a sutileza e a complexidade da comunicação em relações interpessoais recheadas de elementos interativos expressos por oralidade, visualidade, gestualidade, apelos cognitivos, emotivos, psíquicos e de ordem espiritual, que caracterizam as dinâmicas comunicacionais das práticas culturais no Brasil e, quiçá, na América Latina.

A hipótese principal desenvolvida neste artigo é que, na ampla perspectiva comunicacional, e considerando-se as conflituosas condições culturais brasileiras, as CEBs atualizam seu modo de ser através de um conjunto de práticas sociais, múltiplas e diversificadas, rearranjando constantemente as relações comunitárias em que se enredam. Estas práticas sociais centram-se no estabelecimento de parcerias, na circulação de temas e no desenvolvimento de práticas culturais.

Para atualizar essa discussão, refletiu-se acerca do funcionamento das CEBs a partir de um evento realizado em maio de 2019 na cidade de Cuiabá, capital do estado de Mato Grosso, na região Centro-Oeste do Brasil. O cerne do encontro foi o tema do Bem Viver, que se afigura como reatualização utópica e corresponde a uma cosmovisão de povos indígenas andinos orientada pelo bem comum e pela descolonização eurocêntrica do imaginário (Alcântara \& Sampaio, 2016). 
Cuiabá possui pouco mais de 600.000 habitantes $^{1}$ e cerca de 900.000 habitantes no aglomerado urbano que faz com o município de Várzea Grande, nucleando a Região Metropolitana do Vale do Rio Cuiabá (RMVRC). Já o estado de Mato Grosso tem aproximadamente 3.500.000 de habitantes ${ }^{2}$, fazendo divisa nacional com unidades da mesma região Centro-Oeste e com o Norte, além de, a Oeste, fronteira internacional com a Bolívia.

\section{CEBs: Histórico, conceito, organização}

Registra-se a seguir uma revisão sobre o conceito de CEBs, seu lastro histórico, expressão teológica e diálogo com inovações epistemológicas, como a educação popular. Trata-se de um esforço pontuado por pesquisadores e militantes do assunto.

Para José Oscar Beozzo (2012), padre, teólogo e doutor em História Social, as CEBs são resultado de quatro heranças. São elas: a prática pastoral ${ }^{4}$ de Jesus Cristo e as primeiras comunidades de seus seguidores, mais de dois mil anos atrás; o Concílio Vaticano II (1962-1965) e sua influência sobre o plano de ação da Conferência Nacional dos Bispos do Brasil (CNBB); as conferências episcopais latino-americanas, com destaque para a de Medellín (Colômbia), em 1968; e os encontros Intereclesiais, organizados pelas equipes que reúnem e coordenam as Comunidades Eclesiais de Base país afora, de 1975 até hoje.

Conforme uma narrativa bíblica popular, pautada na conexão entre texto escrito e realidade social, Jesus é mostrado como representante de um ser supremo (Deus), que, porém, se fez humano. Nasceu, viveu e transitou cerca de dois mil anos atrás pela Palestina, em meio aos pobres, questionou os poderes religioso, econômico e político - regidos por autoridades locais e obedientes ao

${ }^{1}$ Conforme atualização censitária do Instituto Brasileiro de Geografia e Estatística (IBGE). Acesso em 21 de maio de 2020. Disponível em: <https://www.ibge.gov.br/cidades-eestados/mt/cuiaba.html>.

2 Acesso em 21 de maio de 2020. Disponível em: <https://cidades.ibge.gov.br/brasil/mt/panorama>. 
Império Romano - e acolheu os marginalizados (trabalhador braçal, viúva, deficiente, mulher adúltera etc.). É o que se convencionou chamar de "Cristo histórico".

Beozzo (2012, p. 14) destaca ainda que Jesus vê um primeiro desenho de comunidade "no encontro entre as pessoas e nas relações que estabelecem de cuidado mútuo, amizade, serviço, ternura ou amor". Segundo o livro de Atos dos Apóstolos (Novo Testamento), tais práticas e tal discurso foram mantidos e divulgados pelos discípulos de Cristo após sua morte na cruz, seja por meio de orações, seja pela partilha de alimentos e de bens materiais.

Perseveravam eles na doutrina dos apóstolos, nas reuniões em comum, na fração do pão [rito eucarístico] e nas orações. De todos eles se apoderou o temor, pois pelos apóstolos foram feitos também muitos prodígios e milagres em Jerusalém, e o temor estava em todos os corações. Todos os fiéis viviam unidos e tinham tudo em comum. Vendiam as suas propriedades e os seus bens, e dividiam-nos por todos, segundo a necessidade de cada um. (At. 2: 42-45)

A herança seguinte das CEBs, de acordo com Beozzo, foi o Concílio Vaticano II, convocado pelo Papa João XXIII e concluído pelo Papa Paulo VI. Sintetizou-se numa sequência de encontros com autoridades eclesiais realizada no transcurso de três anos para definir questões de ordem pastoral, doutrinária, de fé e de costumes (moral). A iniciativa buscou reformular a atuação da Igreja, estabelecendo um divisor histórico quanto ao Concílio Vaticano I (entre 1869 e 1870), muito preso ainda a discussões dogmáticas.

A trajetória dos concílios começou no ano 325 e o Vaticano II foi o de número 21, situando-se numa época em que a Igreja Católica era bastante dependente de um modelo europeu e pouco sintonizada com as práticas populares e realidades socioeconômicas de regiões antes colonizadas pelo "Velho Mundo". As resoluções derivadas da sequência de encontros apontaram 
para as seguintes novidades fundamentais: "descolonização", “descentralização" e "desclericalização".

Estímulo à "descolonização" no que tange a um modelo de Igreja eurocêntrico, pressupondo abertura de espaço aos vários rostos das comunidades religiosas católicas espalhadas pelo mundo, com forte impacto nos países da América Latina. Incentivo à "descentralização" no plano hierárquico, permitindo a criação de instâncias de diálogo e participação, envolvendo laicato e clero, a exemplo das Pastorais Sociais ${ }^{3}$ e dos Conselhos Comunitários Pastorais". E impulso ao processo de "desclericalização", valorizando o protagonismo leigo junto a serviços tidos por exclusivos ou prioritariamente "de padres". Entre eles, a celebração (correspondente à missa, mas sem a consagração das hóstias que representam o corpo de Cristo), o ensino da catequese, a preparação para o batismo, a visita aos doentes e idosos e o aconselhamento familiar.

Em parte, esse apelo à "desclericalização" reforçava o chamado catolicismo rústico, analisado em profundidade pela socióloga Maria Isaura Pereira de Queiroz (1968) no contexto de um Brasil habitado por 80.000.000 de pessoas na década de $1960^{5}$. Tratava-se de um tipo de catolicismo popular, praticado principalmente na zona rural, nutrido por laços de vizinhança e costumes religiosos assentados em figuras comunitárias, como o festeiro e o capelão, numa reinterpretação do catolicismo oficial.

De outro lado, o apelo à "desclericalização" abria caminho para a impressão de uma marca própria junto ao ministério de sacramentos e serviços

\footnotetext{
${ }^{3}$ Pastorais Sociais como as da Saúde, da Criança, Carcerária e Operária passaram a promover intercâmbio da Igreja com a sociedade, ultrapassando a estrita dimensão sacramental.

4 Os Conselhos Comunitários Pastorais assumiram-se enquanto espaços de planejamento, avaliação e execução de atividades ligadas ao ambiente religioso, exercitando um senso de democracia intraeclesial.

${ }^{5}$ A população do Brasil hoje possui 211.000 .000 de habitantes e $85 \%$ dela vivem na zona urbana, segundo o IBGE. Acesso em 21 de maio de 2020. Disponível em: $<$ https://educa.ibge.gov.br/jovens/conheca-o-brasil/populacao/18313-populacao-rural-eurbana.html>.
} 
espirituais mais comuns, conectando-os à realidade social envolvente. Essa realidade apontava para as desigualdades da urbanização emergente e a concentração crônica de terras no campo e indicava a organização popular como ferramenta de transformação inspirada no "Cristo histórico".

Os ventos progressistas do Concílio Vaticano II influíram no Plano Pastoral da CNBB e suas diretrizes a partir de 1965, sob os esforços gerais para se ter no Brasil "unidade na Igreja", "catequese e reflexão teológica", "ação ecumênica" e "inserção do povo no social" (Beozzo, 2012, p. 17). Eram elementos que denunciavam implicitamente os pontos conservadores a serem enfrentados à época.

A CNBB foi criada em 1952 para articular a evangelização católica no Brasil e incentivar a colegialidade dos bispos, o que os aproximou do laicato. Os leigos contavam desde 1935 com sua agremiação, a Ação Católica Brasileira (ACB). O termo laicato tem gradações conceituais, sendo algumas das mais conhecidas: o conjunto de fiéis leigos em geral; fiéis leigos engajados ativamente na dinâmica religiosa; e leigos com atuação concomitante na Igreja e na sociedade civil organizada. Já a entidade representativa de padres, freiras e congêneres foi fundada em 1954 (a Conferência dos Religiosos do Brasil CRB).

Nesse contexto organizativo, gradativamente a CNBB passou a desempenhar importante papel quanto à garantia de um viés progressista nos planos teológico e social da Igreja Católica e equilibrar relações com setores conservadores do clero no país, assinalam Kornis e Montalvão (1984). Sendo assim, a CNBB contribuiu para assegurar às CEBs um espaço de atuação, acompanhando-as diretamente, por meio de bispos, padres e freiras referenciais ou na condição de assessores, numa proximidade que pode ser qualificada de amparo, auxílio e/ou tutela.

A mesma aproximação entre clero e laicato ocorreu em conferências episcopais latino-americanas posteriores ao Concílio Vaticano II, principalmente na de Medellín (Colômbia), em 1968, quando as CEBs foram 
enunciadas como experiências iniciantes de um "novo jeito de ser igreja". O documento final do encontro, de autoria do Conselho Episcopal LatinoAmericano (CELAM), destacou que o caráter local e a homogeneidade religiosa de seus grupos eram aspectos a serem potencializados, como se vê a seguir:

A comunidade cristã de base [referência às CEBs] deve, em seu próprio nível, responsabilizar-se pela riqueza e expansão da fé, como também pelo culto que é sua expressão. É ela, portanto, célula inicial da estruturação eclesial e foco de evangelização e atualmente fator primordial da promoção humana e desenvolvimento. (CELAM, 2010, p. 208)

A conferência seguinte, de 1979, em Puebla (México), reconheceu maturidade e crescimento das CEBs no Brasil e na América Latina. As demais edições ocorreram em 1992 (Santo Domingo, na República Dominicana) e 2007 (Aparecida, no Brasil) e fizeram menções menos entusiasmadas às Comunidades Eclesiais de Base.

Já a quarta herança das CEBs, conforme Beozzo (2012), trata de seus encontros de maior magnitude no Brasil, denominados de Intereclesiais, cuja importância pode ser ilustrada pelas temáticas, pelos processos de mobilização, pela dimensão pedagógica e pela riqueza litúrgico-popular. De 1975 a 2018 foram 14 edições, em suma voltadas a refletir sobre a caminhada pastoral, celebrar o encontro de participantes das várias regiões do país e debruçar-se quanto a um assunto em relevo.

O primeiro Intereclesial foi realizado em Vitória (capital do estado do Espírito Santo, região Sudeste do Brasil), com o tema "Uma igreja que nasce do povo pelo Espírito de Deus", e teve algumas dezenas de participantes. A mais recente edição, em 2018, tratou dos desafios do mundo urbano, contou com cerca de 4.000 pessoas e ocorreu em Londrina (no estado do Paraná, região Sul). O próximo Intereclesial, em 2022, será em Rondonópolis (estado de Mato Grosso, região Centro-Oeste), a 200 quilômetros da capital Cuiabá. 
Nesses mais de 40 anos as edições do encontro também refletiram acerca da presença das CEBs nas lutas populares da América Latina, enfocando a percepção e potencialização das culturas oprimidas, o apoio à reforma agrária, a consciência ecológica e a espiritualidade libertadora. Lideranças de pastorais, coordenadores de grupos de reflexão bíblica e agentes de organismos ligados à Igreja, que atuam paralelamente em movimentos sociais, partidos políticos, ONGs, associações de moradores e outras iniciativas, participaram da organização, mobilização, estudo e realização dos Intereclesiais.

Com a promoção média de um encontro a cada quatro anos, os processos de preparação se deram a partir das redes de contatos que integram as CEBs pelo Brasil, seja em pequenas reuniões, grupos de leitura bíblica, celebrações e cursos de formação, seja em romarias, uso de textos-base, cancioneiros das comunidades, atividades de planejamento e avaliação pastoral. Também em retiros, programas em rádios (principalmente comunitárias e educativas e em algumas estações comerciais), jornais, folhetos e cartilhas. Assim como, mais recentemente, por meio de sites, blogs, redes virtuais e aplicativos de mensagens.

Esse trabalho pastoral das CEBs no Brasil se dá não apenas em torno dos Intereclesiais, mas faz parte de seu cotidiano de organização e funcionamento. Viabiliza-se por uma sequência de coordenações, que segue a divisão territorial da CNBB, qual seja, a de 18 regionais para os 26 estados e o Distrito Federal. Cada regional se compõe de arquidiocese (geralmente localizada na capital ou área metropolitana) e dioceses, que se constituem de paróquias, as quais, por sua vez, são compostas por comunidades.

Os representantes das unidades regionais das CEBs formam uma equipe ampliada nacional, compreendida como um serviço de auxílio junto às bases. Essa instância é integrada por lideranças e assessores (que ajudam no contínuo processo de formação). Esse modelo organizativo nacional é repetido no nível regional/estadual, com representantes de arquidioceses e dioceses. E também 
replicado nos municípios que constituem as áreas arquidiocesanas e diocesanas, com membros das coordenações de CEBs das paróquias.

Boa parte das ações de organização, mobilização e animação das CEBs, mais diluídas ou sistematizadas, com maior ou menor grau de estruturação, se vale de processo dialógico e horizontal, resultante da educação popular (sobretudo de matriz freireana). Tal perspectiva ganhou corpo no Brasil na década de 1960, com iniciativas que visavam a conscientizar a população excluída a partir da alfabetização e da cultura popular, assinala Lima (1981), estudioso do pensamento do pedagogo Paulo Freire e propositor do modelo de comunicação-cultura-diálogo que orienta este artigo. Essa confluência histórica reverberou forte presença na metodologia de trabalho das CEBs, favorecendo situações em que prevaleçam postura participativa, trocas de conhecimentos formais e não formais, estímulo à autonomia e à conscientização crítica sobre a realidade.

Essa mesma perspectiva auxilia no processo de viabilização das Comunidades Eclesiais de Base quando se trata do continente América e não apenas do Brasil. Ao todo, as CEBs estão presentes em 20 países, reunidos no Serviço de Articulação Continental. A instância divide-se em: Norte (México, Estados Unidos, Guatemala, Honduras, El Salvador e Nicarágua); CentroAmérica (Costa Rica e Panamá); Caribe (Venezuela, República Dominicana e Haiti); Andina (Colômbia, Bolívia, Peru e Equador); Brasil (país de origem das CEBs); e Cone Sul (Chile, Argentina, Paraguai e Uruguai).

É importante ressaltar que a reunião dessas nações corresponde a um "serviço de articulação" e não a uma "coordenação". Explica-se: o conceito de "articulação" é mais afeito à autonomia das CEBs diante da Igreja Católica e responde à concepção de que fiéis leigos individualizados ou orientados por iniciativas participam do Reino de Deus tanto quanto o clero em geral, o que não significa ruptura com a instituição. Já o conceito de "coordenação" se atém ao modelo da corporação religiosa em meio à sua diversidade interna, com pastorais, organismos, congregações, seminários e outros. 
Por isso o Serviço de Articulação Continental visa a levantar, sistematizar e socializar as mais destacadas experiências de CEBs pelas Américas. Os objetivos se desdobram em funções como a promoção de diálogo altermundista, com as mais diferentes expressões sociopolíticas-econômicas e culturais que postulam por "um outro mundo possível", para além do capitalismo, fundamentalismo, individualismo, consumismo e desenvolvimentismo ${ }^{6}$. Também essas intenções se atualizam por meio de atividades periódicas, a exemplo do Encontro Continental das CEBs, cuja $11^{\mathrm{a}}$ edição ocorreu entre 9 e 12 de março de 2020 em Guayaquil (Equador), envolvendo em torno de 200 lideranças de 16 países ${ }^{7}$.

Essa capilaridade das CEBs não pressupõe, necessariamente, grande número de participantes ou alto poder decisório dentro da Igreja. As Comunidades Eclesiais de Base, ao contrário, cultivam a pequena escala, a dimensão comunitária, a célula que irradia e/ou busca manter-se. Para isso, podem tomar por fonte conceito elaborado em contexto pré-globalização, portanto aberto à ressignificação, pelo frade dominicano e escritor Carlos Alberto Libânio Christo, mais conhecido nos meios cultural e acadêmico como Frei Betto.

Para Betto (1985), as CEBs são "comunidade" porque constituem-se em pequenos grupos que se organizam em torno da paróquia (urbana) ou capela (rural), tendo à frente leigas e leigos, freiras ou padres. "Eclesial" pelo fato de que integrantes se unem não só pela localidade, mas também pela fé e instituição religiosa, pela partilha de dificuldades sociais e produção de soluções conjuntas. "De Base" porque são comunidades "integradas por pessoas que trabalham com as próprias mãos (classes populares)" (Betto, 1985, p. 7).

6 Acesso em 22 maio de 2020. Disponível em: <http://cebsdobrasil.com.br/ 2018/02/18/articulacao-continental-das-comunidades-eclesiais-de-base-o-que-e/> .

7 Acesso em 22 de maio de 2020. Disponível em: <http://cebcontinental.org/index.php/en/39encuentros/encuentros-continentales/708-xi-encuentro-continental-ceb>. 
No chão da realidade, tal definição se apresenta com inúmeras nuances, entre elas as seguintes, presenciáveis nos dias de hoje. Pequenas comunidades com vontade de serem protagonistas de sua fé diante de padres autoritários e exclusivistas. Alianças explícitas entre lideranças religiosas progressistas e parte do clero local. Debates em conselhos pastorais e rodas informais de conversa sobre CEBs como primeira dimensão da Igreja. Jogos simbólicos que perfazem a nada tranquila relação entre comunidades de base e matriz, seguida da crítica ao modelo paroquial centralizado e hierarquizado em detrimento da organização comunitária. E a adesão de parcela das lideranças das CEBs a um formato mais convencional, em parte por assimilação institucional, em parte para buscar maior proximidade com o conjunto do laicato.

Em complemento à conceituação de Betto, acrescida de alguns elementos, recorre-se à teóloga e biblista espanhola Mercedes de Budallés Diez, que atua com as CEBs desde o fim dos anos 1970, especialmente em estados brasileiros da região do Araguaia, como Tocantins (ao Norte do país, já próximo do contexto amazônico), Mato Grosso e Goiás (ambos no CentroOeste). A vivência marcada pela ausência do poder estatal (quando não pelo favorecimento a elites agrárias), pelas necessidades socioeconômicas, pela capacidade articuladora da religiosidade popular e pelas causas de posseiros, pequenos produtores rurais e comunidades indígenas fez com que ela alterasse o modo de conceber e exercer a prática pastoral. Em tom de testemunho, expõe:

Aprendi o que são as CEBs vivendo no meio delas, caminhando com elas, escutando muito, observando o jeito de agir dos participantes. Na comunidade, rezando e refletindo em comunidade. [...] foi a experiência de Deus com as pessoas mais simples, nas suas rezas tradicionais e espontâneas, que fizeram de mim uma teóloga e biblista bem diferente da que veio da Europa. (de Budallés Diez, 2012, p. 119)

Embora destaque a importância dos documentos da Igreja e do livro fundamental do catolicismo (a Bíblia), a teóloga ressalta uma ação inculturada (em diálogo com a religiosidade popular e a dinâmica comunitária). Essa 
postura, apesar e justamente por conta do fluxo de apropriação e reapropriação cultural entre as pessoas envolvidas, faz sentido por estar inscrita no ritmo e no contexto do ambiente onde procurou se inserir.

Outro aspecto concernente às CEBs é a espiritualidade martirial, espécie de culto a figuras da luta popular brasileira e, mais amplamente, do continente América, que "tombaram" na defesa da justiça, seguindo os passos de Cristo (mártir principal). Esse tipo de reverência difere da tradicional devoção aos santos e santas e de sua dimensão milagrosa, assim como do memorial oficial da Igreja, que é perpassado pelo processo de investigação e canonização via Vaticano. A espiritualidade martirial leva em conta a opção pastoral pelas pessoas mais pobres, excluídas e/ou pelas minorias sociais, e por isto inclui, por exemplo, as causas indígena, negra, das mulheres, LGBT, da terra, do trabalho operário, das crianças e jovens.

Nomes comumente mencionados nos santuários, romarias, reuniões e encontros de CEBs são os de Margarida Alves, Chico Mendes, Dorothy Stang e Santo Dias. A primeira era uma sindicalista rural nordestina, que foi assassinada a mando de latifundiários em frente à própria casa em 1983, em Alagoa Grande (estado da Paraíba, no Nordeste brasileiro). Líder seringueiro, Chico Mendes ganhou relevância internacional pela defesa dos povos da floresta e foi morto numa emboscada em 1988, em Xapuri, município onde morava (estado do Acre, Norte do país). Dorothy Stang, religiosa estadunidense naturalizada brasileira, atuava no estado do Pará (também Região Norte) na defesa da reforma agrária e foi morta em 2005, na cidade de Anapu. O metalúrgico Santo Dias participava de um ato grevista em São Paulo (capital do estado de São Paulo, no Sudeste) quando foi assassinado a tiros pela polícia da ditadura, em 1979.

Muitos outros nomes são recordados e atualizados pela difusão de listas de mártires com a narração de suas vidas (martirológios ${ }^{8}$ ) e pelas práticas rituais

${ }^{8}$ Um deles é o blog da Irmandade dos Mártires da Caminhada. Acesso em 22 maio de 2020. Disponível em: < https://irmandadedosmartires.blogspot.com/>. 
de inúmeros movimentos sociais. Não raro os meios progressistas da Igreja Católica e vários movimentos populares também tomam o martirológio como o próprio culto da espiritualidade martirial, expondo uma convergência entre prática e contexto.

O cultivo desse memorial de novo tipo não implica que as CEBs, no entanto, neguem a relação oficial de santas e santos, beatas e beatos. Afinal, uma das energias formadoras das Comunidades Eclesiais de Base, já exposta neste artigo, é o catolicismo rústico "santeiro". Além disso, os processos vaticanistas também podem ganhar feições progressistas, como no caso da santificação em 2018 de Oscar Romero. Há décadas o ex-arcebispo de San Salvador (capital de El Salvador) era tido como mártir por setores progressistas da Igreja Católica e da sociedade latino-americana pela defesa dos direitos humanos, motivo pelo qual foi assassinado pelo Exército salvadorenho em 1980 enquanto celebrava uma missa.

Todo esse avanço no seio da Igreja e da sociedade em geral, expresso pelas CEBs, foi ladeado por uma elaboração teológico-sociológica sobre a realidade latino-americana, cristalizada pelo termo Teologia da Libertação (TdL). Inclusive, pela influência de seus teólogos, autores e entusiastas (como Gustavo Gutiérrez, Juan Luís Segundo, Hugo Assman, Ivone Gebara e Leonardo Boff), a TdL chegou a ser mais conhecida do que as CEBs em alguns espaços, entre eles a academia e parte dos movimentos sociais. Essa é uma das razões pelas quais não raro se considera um termo sinônimo do outro.

Contudo, uma teologia estuda o âmbito religioso em suas conexões com variados campos do conhecimento, postula ideias, apresenta metodologias. Isto não se confunde com a existência própria de fenômenos do universo sociocultural, tais quais as Comunidades Eclesiais de Base, explica o teólogo, filósofo e escritor Clodovis Boff, que complementa':

[...] a originalidade da Teologia da Libertação não está somente na abordagem do tema opressão/libertação como objeto da reflexão

\footnotetext{
${ }^{9}$ Clodovis foi um destacado teólogo da libertação, porém por volta de 2007 rompeu com a TdL.
} 
teológica, mas sim [em que] ela reivindica esta novidade enquanto é uma reflexão de fé a partir e no interior da prática de libertação, o que não é simplesmente refletir de forma teórica sobre a libertação, mas sobre a prática concreta da libertação feita pelos pobres e por seus aliados junto com os pobres. $(1984$, p. 25$)$

A retroalimentação entre TdL e CEBs é mais um elemento do arcabouço conceitual relativo às Comunidades Eclesiais de Base e suas articulações epistêmicas, marcadas por algumas camadas de sentido, como o complexo exercício de autonomia do laicato com vistas à constituição de uma "Igreja Povo de Deus" concomitante ao simbolismo e à efetividade da concepção hierárquica. Novas filigranas poderão ser vistas no próximo tópico do artigo, na medida em que se vale do trabalho de campo para detalhar o funcionamento das CEBs.

\section{CEBs: Atualizações, repetição e singularidades}

Nos dias atuais, as CEBs realizam diversos eventos que razoavelmente se repetem em diferentes cidades e estados, mantendo nomes e propostas de funcionamento similares. Também existem atividades singulares, em função de condições sociopolíticas, aspectos geográficos, pautas mais prementes na região, características identitárias e culturais da população local envolvida.

No geral, as formas de expressão mesclam práticas peculiares das CEBs com influências do catolicismo rústico, do devocionismo "santeiro" e da organização institucional/paroquial da Igreja.

Além disso, no contato com minorias sociais, movimentos populares, congregações religiosas, campanhas socioeclesiais da $\mathrm{CNBB}$, entre outros, as Comunidades Eclesiais de Base assimilam ou se deixam embeber por práticas culturais e temáticas que possibilitem pontes com sua concepção espiritual e linha de atuação.

Neste artigo, concentra-se a pesquisa no fazer sociocultural das CEBs a partir de um evento realizado de 17 a 19 de maio de 2019, qual seja, o I 
Encontro Juventude e Bem Viver - CEBs Arquidiocese de Cuiabá, na capital do estado de Mato Grosso.

As atividades se realizaram na Comunidade São José Operário, que pertence à paróquia de mesmo nome e situa-se no bairro Dom Aquino, a poucos quilômetros da região central, uma das mais urbanizadas da cidade.

Se a comunidade religiosa acolhe o nome do pai de Jesus adicionado à sua condição de carpinteiro, o nome do bairro remete a Francisco de Aquino Correia, governador de Mato Grosso de 1919 a 1922 e arcebispo de Cuiabá de 1922 a 1956. De modo geral, o bairro Dom Aquino tem cerca de 13.000 moradores, perfil socioeconômico de renda média e bom atendimento de serviços básicos, como saneamento e coleta de lixo, segundo dados da Prefeitura $^{10}$.

O encontro das CEBs reuniu em torno de 50 pessoas de Cuiabá e de municípios próximos (Várzea Grande e Jangada), boa parte engajada em Comunidades Eclesiais de Base em seus municípios de origem, mas também adolescentes que participam de algum trabalho pastoral da Igreja, além de integrantes de movimentos sociais e congregações religiosas.

Várzea Grande possui a segunda maior população de Mato Grosso, com aproximadamente 280.000 habitantes $^{11}$, e integra a área metropolitana da Grande Cuiabá, fazendo divisa com a capital. Jangada dista cerca de 80 quilômetros da cidade-sede do encontro, tem menos de 8.500 moradores $^{12}$ e a maioria vivia na zona rural, segundo o censo mais recente, de $2010^{13}$. Além dos municípios citados, a arquidiocese de Cuiabá engloba Acorizal, Barão de Melgaço, Nobres, Rosário Oeste e Santo Antônio do Leverger ${ }^{14}$.

10 Acesso em 23 de maio de 2020. Disponível em: <http://www.cuiaba.mt.gov.br/ upload/arquivo/composicao_bairros.pdf>.

11 Acesso em 22 de maio de 2020. Disponível em: <https://cidades.ibge.gov.br/ brasil/mt/varzea-grande/panorama>.

12 Acesso em 23 de maio de 2020. Disponível em: <https://cidades.ibge.gov.br/brasil/mt/ jangada/panorama>.

13 Acesso em 23 de maio de 2020. Disponível em: < http://sit.mda.gov.br/download/caderno/ caderno_territorial_016_Baixada\%20Cuiabana\%20-\%20MT.pdf>.

${ }^{14}$ A Arquidiocese de Cuiabá inclui ainda o Distrito da Guia, pertencente à capital. 


\subsection{Parcerias}

O estabelecimento de parcerias no que tange ao encontro pesquisado é o primeiro tópico a ser detalhado. O desenvolvimento de relações evidencia o trânsito das CEBs, principalmente junto aos movimentos populares. No Encontro da Juventude e Bem Viver, na cidade de Cuiabá, relacionam-se distintas entidades/iniciativas presentes (participantes ou apoiadoras do evento): Associação dos Docentes da Universidade Federal de Mato Grosso (ADUFMAT); Federação Nacional dos Bancários; Centro Burnier Fé e Justiça; Central Única dos Trabalhadores (CUT); CIMI; CPT; Cáritas Nacional (organismo da Igreja para projetos sociais); Um Grito pela Vida (combate ao tráfico humano); Favela Ativa (grupo de periferia que lida com arte e projetos sociais); Centro de Estudos Bíblicos (CEBI); MST; Economia Solidária (movimento balizado por relações de comércio justo, sem patrões nem empregados e respeito à natureza); mandato de uma deputada federal do Partido dos Trabalhadores (PT) em Mato Grosso; congregações das Irmãs da Divina Providência e das Filhas de Maria Auxiliadora.

As parcerias foram importantes para a realização do encontro. Contribuíram com a definição de metodologia e a mobilização, além da cessão de espaço físico. Auxiliaram no financiamento para pagar as passagens de avião do assessor que ministrou o tema do evento (dirigente do CIMI). E garantiram kits a quem participou do evento (bolsas, crachás, pastas, cadernos, canetas e canecas), alimentos, combustível para deslocamento, entre outros.

O primeiro tipo de auxílio se deu na ampliação da equipe de trabalho, com pessoas somadas à coordenação arquidiocesana das CEBs, que trocaram informações e viabilizaram encaminhamentos em reuniões presenciais e contatos on line (WhatsApp). A esse serviço foram agregados integrantes do CEBI (associação ecumênica voltada ao fomento da leitura popular da bíblia), que anos atrás participavam da Pastoral da Juventude (PJ, setor da Igreja identificado com a espiritualidade das CEBs), pelo costume de realizar encontros para jovens. 
Também se juntaram à equipe lideranças da paróquia que sediaria o encontro, para estreitar diálogo com o pároco e conseguir famílias que hospedassem participantes de outros municípios - remontando a prática dos discípulos de Cristo ao saírem para anunciar o seu evangelho, conforme registro no livro bíblico de Atos dos Apóstolos. Tal expediente é corriqueiro nas atividades das CEBs com maior duração e tem ápice nos Intereclesiais, quando milhares de pessoas de outras cidades e estados são acolhidas por fiéis leigas e leigos que moram nos municípios que os recebem.

A procura por ajuda e a disponibilidade de auxílio quanto ao evento em Cuiabá se explicam pela lista de parcerias mais próximas das Comunidades Eclesiais de Base da arquidiocese, pelo histórico das CEBs e sua inserção social, além dos contatos que cada liderança possui junto a sindicatos, movimentos e similares, seja na dimensão da militância, na condição de estudo e/ou trabalho. Seguem alguns exemplos para tornar mais explícita a configuração desse trânsito.

O apoio da ADUFMAT ocorreu em função de uma das articuladoras das CEBs ser estudante da Universidade Federal de Mato Grosso (UFMT) e já ter participado da organização de alguns eventos com a associação. O auxílio obtido junto ao mandato da deputada ocorreu porque várias membras e membros das CEBs, organismos e entidades que estão no entorno delas têm proximidade com o PT, partido criado em 1980 com o empenho também de setores progressistas da Igreja Católica. O apoio da Federação dos Bancários se deu porque um de seus dirigentes já foi membro da PJ e mantém laços com colegas de militância. O auxílio das congregações das irmãs religiosas foi possível pela afinidade quanto ao modo de atuação pastoral, de caráter humanista.

Esse trânsito incorpora movimentos sociais de matriz socioeconômica e hierarquizada (majoritários no século passado, de cunho classista, como os sindicatos, suas federações e confederações) e novos movimentos sociais. Estes últimos, de acordo com a cientista social Ilse Scherer-Warren (2005), foram 
forjados nos anos 1970, focando-se nas múltiplas questões da identidade, de modo descentrado, com horizontalidade de poder, conectando lutas locais, nacionais e internacionais.

A composição dessa teia de contatos na construção do encontro das CEBs se faz não apenas pelo atendimento de um pedido de auxílio. Converte-se em fluxo de troca de informações, ideários, compromissos e projeções, uma vez que promove reencontros de pessoas, confirmação de parcerias, promessa de contrapartida, abertura para assuntos e abordagens específicas que contribuem com a ampla circulação de temas, como se verá no tópico a seguir.

Ainda que as CEBs não sejam um movimento social, dado que se assentam na condição de "modo de ser Igreja Povo de Deus", seu diálogo com inúmeras iniciativas militantes progressistas da sociedade civil é histórico e recorrente. Por isso, essas parcerias aproximam-se do que diz a socióloga Maria Glória Gohn (1995, p. 44), a saber, que os movimentos sociais "politizam suas demandas e criam um campo político de força social na sociedade civil", posto que suas "ações desenvolvem um processo social e político-cultural que cria uma identidade coletiva do movimento, a partir de interesses em comum".

Anota-se, todavia, que a maneira de constituir a rede organizativa do encontro em tela, ritmado epistemicamente por um saber-fazer resultante da repetição e aperfeiçoamento de lógicas e procedimentos, também foi marcada por jogos simbólicos e variados desdobramentos. Essas manobras incluíram: a ampliação do escopo de participantes, prevendo que não se conseguisse preencher as vagas com apenas ou prioritariamente o público jovem, e a modulação do tom de diálogo com o pároco e a comunidade acolhedora, considerando os perfis mais devocionais e menos progressistas dos mesmos.

\subsection{Temáticas e diálogos}

Outra categoria bastante expressiva no trabalho de campo relativo ao evento em Cuiabá foi a circulação temática (de assuntos) possibilitada pela 
discussão do tema central, que envolveu juventude e Bem Viver. Em primeiro lugar, o foco geracional foi definido em razão de uma demanda constante no seio das CEBs, qual seja, a necessidade de se aproximar de jovens, para dinamizar a renovação de participantes e lideranças, cuja presença maior é de adultas/adultos e idosas/idosos. Por outro lado, adolescentes e jovens que participam das CEBs, assim como integrantes da $\mathrm{PJ}$, reivindicam um acolhimento maior, expresso por temáticas, metodologias e abertura de espaço para atuação.

A questão passa pelo caráter plural e difuso da juventude em meio à contemporaneidade. Envolve as marcas do consumismo e individualismo, as diversas formas de sociabilidade e exclusão social. Compreende a concepção da/do jovem enquanto sujeito de direitos e protagonista da própria trajetória, e como isto impacta na sua relação com a vivência da fé. E, ainda mais, na espiritualidade pautada em um Deus libertador, conforme texto que orientou plenária sobre o assunto no $14^{\circ}$ Intereclesial das CEBs ${ }^{15}$.

Em segundo lugar, o tema do Bem Viver foi elencado por sintetizar uma nova concepção de sociedade, capaz de reatualizar a construção do "Reino de Deus aqui na Terra", como se fala nas Comunidades Eclesiais de Base. Há alguns anos o termo é refletido pelas CEBs e vem ganhando uma certa centralidade em encontros, debates, rituais espirituais, reuniões de planejamento e avaliação.

Recuperado da experiência milenar de povos indígenas da América do Sul, desde o sul da Venezuela até o norte da Argentina, o Bem Viver funda-se em uma perspectiva de vida equilibrada e harmoniosa com o lugar onde se habita. A expressão vem do kíchwa e do aymara, idiomas pré-hispânicos da região andina, e de outras línguas indígenas, como o guarani.

Convertido em plataforma para um projeto de sociedade, o Bem Viver significa negar a premência do capitalismo, uma vez que implica: mudança na

15 Acesso em 23 de maio de 2020. Disponível em: <http://cebsdobrasil.com.br/2018/01/25/odesafio-das-juventudes-verjulgar/>.

Revista Cultura \& Religión Vol. XV, 2021 Nº 1 (enero-junio) 
forma de pensar e agir, pondo o bem comum acima de interesses individuais, e em necessidade urgente de estabelecer limites ao consumo para evitar o suicídio coletivo da humanidade.

O Bem Viver almeja uma ecologia integral (ambiental, econômica, social, cultural, humana, da vida cotidiana, urbana, rural, educacional, espiritual) e baliza as Constituições Federais de países como Equador e Bolívia. É o que aponta o economista equatoriano e um dos maiores estudiosos do assunto, Alberto Acosta.

Por isso o pesquisador observa que:

o Bem Viver com sua proposta de harmonia com a Natureza, reciprocidade, relacionalidade, complementariedade e solidariedade entre os indivíduos e comunidades, com sua oposição ao conceito de acumulação perpétua, com seu regresso ao uso, o Bem Viver, enquanto ideia em construção, livre de preconceitos, abre as portas para formular visões alternativas de vida. (Acosta, 2016, p. 33)

A partir desse tema central, do fluxo conceitual decorrente da presença das entidades parceiras, das histórias de vida e militância de participantes do encontro, uma teia imensa de assuntos foi confeccionada, excedendo o tipicamente religioso. $\mathrm{O}$ tecido temático envolveu a compreensão conceitual, o histórico e a percepção de exemplos concretos de Bem Viver e o Sínodo da Pan-Amazônia (encontro do Papa Francisco com bispos, em outubro de 2019, no Vaticano, para discutir a atuação da Igreja na região após diálogos com povos da floresta). Expôs a demarcação das terras indígenas - tema sensível em Mato Grosso, estado em que existem mais de 40 etnias e em que $12 \%$ de seu território pertence a elas.

Incluiu a defesa da agroecologia, agricultura familiar e sementes crioulas (variedades desenvolvidas, adaptadas ou produzidas por populações tradicionais) em contraponto ao modelo econômico majoritário em Mato Grosso, que é o agronegócio de exportação excessivo em agrotóxicos. 
Também trouxe: a identidade e espiritualidade libertadora das CEBs; a comunicação popular/alternativa e a leitura crítica da mídia; os conceitos de "juventudes" e de "ser jovem"; e as reflexões sobre morar no campo e "ser/sentir-se camponês", sobretudo pela presença de jovens de Jangada que têm contato com a realidade de assentamentos rurais.

A teia temática englobou, ainda: defesa da educação pública e posição contra cortes orçamentários no setor pelo Governo Federal; mobilização contra o tráfico humano; combate à pedofilia; leitura popular da bíblia; feminismo; postura progressista do Papa Francisco, com a defesa da igualdade social e dos povos indígenas; importância de ser saudável, ter boa alimentação e viver feliz.

$\mathrm{E}$ mais assuntos foram registrados, tais como a crítica à Reforma da Previdência (Proposta de Emenda à Constituição com aumento do tempo de contribuição e idade para aposentadoria); situação precária de imigrantes da Venezuela e do Haiti em Cuiabá; protagonismo de fiéis leigas e leigos em contraponto ao clericalismo (supervalorização do clero pela Igreja e por parcela considerável do laicato).

Essa miscelânea, potencializada pela discussão central do encontro, também incorpora um movimento paralelo, de reflexão acerca de questões próprias das CEBs, bem como se estende para discussões da Igreja em geral e, ao mesmo tempo, aproveita a circunstância para divulgar tópicos pouco conhecidos do público participante.

Confirma, assim, um caráter de espraiamento, tentacular, já visto no exercício das parcerias que, para além da conformação eventual, conserva laços históricos, mas vai retomando algumas pontas soltas pelo caminho e encontrando outras, que poderão ou não ser reconectadas, dependendo das condições objetivas de disposição e interesse e da conjuntura sociocultural, que tanto fortalece quanto distancia associações.

Pois esse modo de ser das CEBs, explicitado pelo seu fazer sociocultural, está mais para o flexível, para a interconexão e para a contínua lida de "virar-se" com o que se tem em mãos. São práticas afirmativas, que 
brotam das relações entre seus membros e que delas proliferam, mais instaurando formas e processos do que seguindo modelos estabelecidos.

Portanto, esse modo de fazer das Comunidades Eclesiais de Base enuncia uma imensa dificuldade de explicar como funciona a realidade quando se abre mão de fórmulas acabadas e ideias totalizantes e se opta por debruçar-se sobre a produção de operações mínimas, dentro do raio concreto de ação de grupos e pessoas.

Porém, nesse momento de inflexão podemos acorrer ao antropólogo Clifford Geertz (2017, p. 4), lembrando que a existência humana, sublinhada por sistemas entrelaçados de signos, toma a cultura "não como uma ciência experimental em busca de leis, mas como uma ciência interpretativa, à procura de significado".

Nesse sentido, a grande circulação de assuntos no encontro das CEBs não resulta apenas de uma amálgama de protagonistas sociais que, ao se juntarem, trazem consigo suas demandas e as põem em comum para dialogar. Subentende um espraiamento balizado por uma espiritualidade de caráter libertador, com vistas a um horizonte utópico, que se valida na medida em que se projeta, se expõe, se instabiliza, se retoma - nem sempre consciente do que foi alterado e/ou apreendido no caminho - e segue em frente.

\subsection{Práticas culturais}

Por fim, menciona-se o rol de práticas culturais percebidas no evento, comuns à lida comunitária das CEBs. Para caber no formato do artigo, foram reunidas neste tópico duas categorias, quais sejam, as atividades do encontro e as metodologias utilizadas para dinamizá-lo. Abaixo, seleção de práticas culturais presentes no evento:

- recepção (acolhida);

- hospedagem solidária;

- apresentação de cada participante; 
- animação (músicas, dinâmicas e danças);

- análise coletiva da realidade;

- fila do povo;

- grupos de discussão;

- socialização;

- oficinas;

- encaminhamento de ações concretas;

- avaliação do encontro; e

- místicas.

A seguir descreve-se de maneira sucinta o que significa cada uma dessas práticas culturais. Para efeito didático, ajuntam-se algumas delas, por ocorrerem várias vezes de forma interdependente.

Recepção - É denominada costumeiramente de acolhida. Envolve cumprimentos afetuosos entre equipe de organização e participantes, informes sobre programação e logística. É um primeiro gesto de amabilidade, concernente ao que se chama de "gratuidade". Baseia-se numa perspectiva de amor incondicional - simbolizada pela história de Cristo - e modulada pela reciprocidade afetiva das partes.

Hospedagem solidária - Também é chamada de acolhida. Subentende contato mais próximo entre dona/dono da casa e visitante, com troca e partilha. Para quem hospeda, demanda zelo no preparo da cama e de algumas refeições. Para quem visita, corresponde permanecer num lugar geralmente desconhecido e assimilar a experiência sob um fundo comunitário.

Apresentação de participantes e técnicas de animação - A menção de nomes, cidades de origem e atuações pastorais ocorre em atmosfera lúdica, pontuada por dinâmicas, músicas, gestos e danças, intentando criar um ambiente favorável à convivência. Esse desafio é renovado constantemente pela presença de pessoas pouco conhecidas no meio. Em geral, o tom lúdico 
perpassa toda a atividade e não só a apresentação, tal como se viu no encontro pesquisado.

Análise coletiva da realidade - Foi seguida no evento pela fila do povo. A análise coletiva corresponde a uma espécie de versão mais democrática da tradicional análise de conjuntura feita na academia, partidos políticos e movimentos populares. $\mathrm{O}$ formato mantém o caráter generalista de uma análise conjuntural, trabalha com reflexões em vez de determinar caminhos e inclui outras dimensões ao viés socioeconômico, como a ecológica e a eclesial.

Fila do povo - É um espaço para comentários de participantes - não necessariamente em busca de respostas de palestrantes - e manifestações mais difusas, bem como para expressões de caráter artístico, na forma de poesias e trechos de cantos. Chama-se de fila porque em eventos com maior público as pessoas se agrupam em pé, umas atrás das outras em direção ao microfone.

Formação de grupos de trabalho - No encontro em Cuiabá esta prática ajuntou-se à socialização. Os grupos funcionaram a partir de questionário a ser respondido ou de provocação geral, conforme proposição da equipe organizadora ou das assessoras/assessores. Houve momentos em que as/os participantes se reuniram para cochichar (expor em alguns minutos suas impressões) e, outros, para argumentar demoradamente.

Socialização - Os resultados dos trabalhos em grupo foram expostos ao público geral, via explanação oral e entrega de anotações à secretaria, responsável por registrar a memória do evento. Além de servir à partilha de discussões, a socialização democratiza o uso da fala e estimula o protagonismo de participantes, sendo, por isto, um mecanismo de formação de lideranças.

Oficinas - A inserção desta prática cultural das CEBs ocorre em eventos com programações mais extensas. Objetiva garantir diferentes maneiras de experienciar os temas centrais e valorizar o fazer prático. No evento, as oficinas trataram de: agroecologia; economia solidária; comunicação popular; arte e cultura popular. 
Encaminhamento de ações concretas - Busca assegurar repercussão "na comunidade", ressaltando uma espiritualidade que conecta fé com vida cotidiana. As pontuações efetuadas ao final do encontro foram bem palpáveis, como: manter a união das/dos participantes; realizar novos eventos com a juventude; estender a proposta do Bem Viver às comunidades a partir do diálogo e não da imposição.

Mística - É uma prática cultural capaz de exprimir, com densidade, a espiritualidade presente nas CEBs. Traz elementos da religiosidade popular, liturgia inculturada, crítica social e protagonismo do leigo. Conjuga oração, meditação, leitura bíblica, gestualidade, canto, dança, entre outros elementos e, geralmente, é conduzida pelos leigos, mesmo havendo presença de membros do clero. Devido a essa intensidade simbólica, a mística pode ser vista como sinônimo de "espiritualidade das CEBs". ${ }^{16}$

Avaliação - Realizada ao final do encontro, sua ocorrência compreende a crítica e a autocrítica de quem participou das atividades. Serve de base ao aperfeiçoamento dos próximos eventos e de reflexão quanto ao conhecimento apreendido, convívio estabelecido e ações a serem desempenhadas nas comunidades. No encontro, os apontamentos foram feitos oralmente e dividiram-se em pontos positivos, negativos e sugestões.

Em suma, as práticas culturais elencadas encontram ressonância na abordagem da "ciência do comum", proposta epistemológica de Sodré. A postulação baseia-se na vinculação social via dimensão interpessoal, dado que a condução do evento pesquisado se deu, sobretudo, a partir de um fazer coletivo, artesanal e em torno da produção de afetividades.

A proposta do acadêmico toma o diálogo por central, enxergando-o não como mero intercâmbio de palavras, mas como ação de fazer ponte entre as diferenças, que concretiza a abertura da existência em todas as suas dimensões e constitui ecologicamente o homem no seu espaço de habitação - portanto, diálogo como categoria ética. (Sodré, 2014, p. 191)

${ }^{16}$ Mística, num nível anterior e mais amplo, corresponde à noção de "experiência de Deus". 
Essa centralidade do diálogo permeia práticas culturais das CEBs, seja nos grupos de trabalho, socializações, filas do povo ou no processo avaliativo, bem como se reveste de uma dimensão espiritual e afetiva, presente na acolhida, hospedagem solidária ou nas místicas. Apesar de seu tom democrático e participativo, destaca-se uma interioridade caracterizada por uma fluência mais dada à sociabilidade e ao extralinguístico do que à socialização verbal e ao linguístico, porque “o comum” é sentido antes de pensado, explica Sodré (2014, p. 204).

Angulada pelo campo da Comunicação, a proposição epistemológica do autor prioriza a "comunicação do comum", atividade social preexistente ao modelo de produção midiática. Leva em conta que a comunicação ocorre com o envolvimento da comunidade, da vinculação social e do comum, projetando-se em um espaço físico-simbólico marcado pela conexão afetiva e dialógica quanto ao que pode ser sentido e compartilhado.

\section{Considerações finais}

Este artigo buscou abordar as dinâmicas comunicacionais de uma expressiva iniciativa sociocultural latino-americana, a partir de seus modos de fazer, no chão de suas ações costumeiras e contemporâneas, além de problematizar seu percurso histórico e sua identidade. Acredita-se que este perfil de pesquisa, pautado pelo trabalho de campo e aberto às surpresas que a lida em cena pode proporcionar ao observador participante, corrobora para dinamizar a produção científica.

Tão importante quanto trazer o caminho percorrido pelas CEBs no Brasil é dizer por onde e como elas têm se deslocado em meio à sociedade contemporânea, o que se faz, por exemplo, por meio de estudos de caso como o mostrado neste artigo, atualizando assim as pesquisas acerca do assunto.

Esse tipo de investida pode ganhar mais relevo se realizado sob um novo enfoque. Foi o que se buscou a partir da Comunicação na interface com a 
Cultura, ampliando a variedade de abordagens, abrindo o espaço para outras epistemologias e revigorando projetos societários emancipatórios no contexto da América Latina.

Desta forma, a escolha metodológica do estudo de caso mostrou alguns aspectos inquietantes das CEBs no local investigado, qual seja, em Cuiabá, capital de Mato Grosso, Região Centro-Oeste do Brasil, em um evento reunindo integrantes principalmente desta cidade, mas também de municípios próximos. Um desses aspectos é a disposição de um grande volume de conexões no seu modo de fazer, que podem ser vistos no rol de parceiros, na quantidade de temáticas circulantes (assuntos variados) e nas práticas culturais desenvolvidas.

Quanto às parcerias, viu-se uma capacidade plástica das CEBs de dialogarem com movimentos progressistas de corte mais clássico (como partidos e sindicatos), assim como entes de caráter contemporâneo, pautados por questões da subjetividade e da arte, além de instâncias internas da Igreja partícipes de suas causas.

A grande quantidade de temas circulantes no evento se deu por conta de um modelo organizativo aberto e solícito de colaborações e pelas metodologias interativas, que mobilizaram diversas formas de expressão junto aos participantes.

Já as práticas culturais expuseram a indiscernibilidade entre comunicação e cultura nas CEBs, uma vez que a dimensão comunicacional transpareceu nas múltiplas atividades realizadas durante o encontro, perfazendo uma intensa produção de sentidos nos campos racional, artístico, afetivo e espiritual.

Um outro aspecto inquietante das CEBs no local investigado é o seu caráter propositivo-afirmativo, que: parte de uma posição crítica dentro da Igreja Católica e quanto à sociedade em geral; procura estabelecer diálogos possíveis; recua diante de recrudescimentos institucionais; retoma contatos desgastados; produz novas associações; e exercita a autoavaliação como um elemento a mais em um processo permanente de retroalimentação de sentidos. 
Percepções como essas geralmente escapam ao radar das macroanálises e, nota-se, apontam para um rico potencial criativo das Comunidades Eclesiais de Base. Dessa maneira, contribuem para que se tornem objetos de estudo menos centrados no passado de luta contra a ditadura, investidas pró-cidadania e ligação com a Teologia da Libertação.

Longe de apagar tais marcas constitutivas, corrobora-se para mostrar que as CEBs continuam construindo-se enquanto elemento dinâmico da História e funcionam a partir de um conjunto de parâmetros bem maior do que o consolidado academicamente - alguns revitalizados, outros desvelados. Essa investida epistemológica estimula a produção de estudos que avancem do âmbito discursivo para o extralinguístico, como diz Sodré.

Sendo assim, esse tipo de pesquisa compreende adentrar um terreno emaranhado de sentidos, ao mesmo tempo que caracterizado pelo difusionismo missionário da religião católica. Essa complexa seara permeia tanto o arcabouço histórico e conceitual da Igreja, com inúmeros segmentos e formas de espiritualidade, quanto as singularidades que marcam as Comunidades Eclesiais de Base, viabilizadas em muito pelo manejo cultural do laicato e pelo diálogo com organizações da sociedade civil.

Essa teia de sentidos mostra um fluxo contínuo de distinções, conexões, distanciamentos, rechaços e reconfigurações, apontando a viabilidade de uma abordagem científica calcada no modelo comunicacional dialógico em interface com a interpretação cultural.

\section{Referências}

Acosta, A. (2016). O Bem Viver: uma oportunidade para imaginar outros mundos. São Paulo: Autonomia Literária/Elefante.

Alcântara, L. S. \& Sampaio, C. A. C. (2017). "Bem Viver como paradigma de desenvolvimento: utopia ou alternativa possível?". Desenvolvimento e

Meio Ambiente, Curitiba, 40, pp. 231-251. Visitado em 13 de abril de 
2020. Recuperado a partir de: <https://revistas.ufpr.br/ made/article/view/48566/32108>.

Alves, L. M. A. (2008). Movimentos sociais em Mato Grosso: Desafios e conquistas (1974-1989). Cuiabá: EdUFMT.

Atos dos Apóstolos. (1992). In: A Bíblia. São Paulo: Ave Maria.

Barbosa, J. D. de A. (2008). As Comunidades Eclesiais de Base - CEBs: nas décadas de oitenta e noventa em Cuiabá - Mato Grosso. Espaço popular de construção de cidadania? Dissertação de mestrado em Educação. Programa de Pós-graduação em Educação, Universidade Federal de Mato Grosso. Cuiabá, Mato Grosso, Brasil.

Beozzo, J. O. (2012). "As CEBs e seus desafios hoje: um olhar sobre a conjuntura e a história". In: F. Orofino, S. R. Coutinho \& S. S. Rodrigues (organizadores). CEBs e os desafios do mundo contemporâneo (pp. 11-30). São Paulo: Paulus.

Betto, F. (1985). O que é Comunidade Eclesial de Base. São Paulo: Brasiliense.

Boff, C. (1984). Teologia Pé-no-chão. Petrópolis: Vozes. de Budallés Diez, M. (2012). "Um testemunho sobre a vida das CEBs no Centro-Oeste". In: : F. Orofino, S. R. Coutinho \& S. S. Rodrigues (organizadores) CEBs e os desafios do mundo contemporâneo (pp. 119-134). São Paulo: Paulus.

Conselho Episcopal Latino-Americano (CELAM). (1968). Conclusões da Conferência de Medellín/1968. Texto oficial. São Paulo: Paulinas.

Delgado Molina, C. A. (2018). "Modelos culturales de mujeres católicas de los activismos conservadores en Argentina". Revista Cultura \& Religión, 12(2), pp. 43-65. Visitado em 05 de abril de 2021. Recuperado a partir de https://www.revistaculturayreligion.cl/index.php/revistaculturay religion/article/view/830

Fonseca, J. (2002). Metodologia da pesquisa científica. Fortaleza: UEC.

Garcés, R. (2019). "La Santa Muerte en la Ciudad de México: devoción, vida cotidiana y espacio público". Revista Cultura \& Religión, 13(2), pp. 
103-121. Visitado em 05 de abril de 2021. Recuperado a partir de https://www.revistaculturayreligion.cl/index.php/revistaculturayreligion/ article/view/848

Geertz, C. (2017). A interpretação das culturas. Rio de Janeiro: LTC.

Gerhardt, T. \& Silveira, D. (2009). Métodos de pesquisa. Porto Alegre: UFRGS.

Gohn, M. G. (1995). Movimentos e lutas sociais na história do Brasil. São Paulo: Loyola.

Granados Valdéz, J. (2020). "Estética de la alegría del sacrificio. Anacronismo de la modernidad". Revista Cultura \& Religión, 14(1), pp. 13-25. Visitado em 04 de abril de 2021. Recuperado a partir de https://www.revistaculturayreligion.cl/index.php/revistaculturayreligion/ article/view/839

Gushiken, Y. (2006). "Dialogismo: Emergência do pensamento latinoamericano em comunicação". Comunicação, Mídia e Consumo, 3(8), pp. 70-91. Visitado em 20 de setembro de 2020. Recuperado a partir de: $<$ http://revistacmc.espm.br/ index.php/revistacmc/article/view/81/82>.

Kornis, M. \& Montalvão, S. (2009). Conferência Nacional dos Bispos do Brasil (CNBB). In Dicionário Histórico-Biográfico Brasileiro pós-1930. (Verbete). Rio de Janeiro: CPDOC/FGV. Visitado em 15 de julho de 2020. Recuperado de: <http://www.fgv.br/cpdoc/acervo/dicionarios/ verbete-tematico/conferencia-nacional-dos-bispos-do-brasil-cnbb>.

Leonardi, Y. A. (2020). "La propuesta cultural de los Círculos Católicos de Obreros en la Argentina durante las primeras décadas del siglo XX". Revista Cultura \& Religión, 14(2), pp. 1-16. Visitado em 03 de abril de 2021. Recuperado a partir de https://www.revistaculturayreligion.cl/ index.php/revistaculturayreligion/article/view/820

Lima, V. A. (1981). Comunicação e cultura: as ideias de Paulo Freire. Rio de Janeiro: Paz e Terra. 
Lima, V. A. (2001). Mídia: teoria e política. São Paulo: Perseu Abramo.

Marins, J. (2015). Fomos a um Concílio: a surpresa do Vaticano II. São Paulo: Paulus.

Menezes, D. H. L. (2010). CEBs e Redes de Comunidades: Abordagem teológico-pastoral a partir de Faustino Teixeira e do material dos Encontros Intereclesiais das CEBs. Dissertação de mestrado em Teologia Sistemática. Faculdade Jesuíta de Filosofia e Teologia, Belo Horizonte, Minas Gerais, Brasil.

Minayo, M. C. S. (2002). "Ciência, técnica e arte: o desafio da pesquisa social”. In: M. C. S. Minayo (organizadora). Pesquisa social: teoria, método e criatividade (pp. 9-29). Petrópolis: Vozes.

Orofino, F., Coutinho, S. \& Rodrigues, S. (orgs. 2012). CEBs e os desafios do mundo contemporâneo. São Paulo: Paulus.

Queiroz, M. I. P. de. (1968). "Sociologia - O Catolicismo Rústico no Brasill”. Revista do Instituto de Estudos Brasileiros, (5), pp. 104-123. Visitado em 20 de junho de 2020. Recuperado de: http://www.revistas.usp.br/ rieb/article/view/45715/49311.

Ros Codoñer, J. (2018). "Claves para una Sociología de la Experiencia Religiosa en el ámbito católico.” Revista Cultura \& Religión, 12(1), pp. 54-74. Visitado em 03 de abril de 2021. Recuperado a partir de https://www.revistaculturayreligion.cl/ index.php/revistaculturayreligion/article/view/805

Santos, I. M. F. (2006). Luta e perspectivas da Teologia da Libertação: o caso da Comunidade São João Batista, Vila Rica, São Paulo: 1980-2000. Dissertação de mestrado em História, Faculdade de Filosofia, Letras e Ciências Humanas, Universidade de São Paulo. São Paulo, Brasil.

Scherer-Warren, I. (2005). Redes de movimentos sociais. São Paulo: Loyola.

Sodré, M. (2014). A ciência do comum: Notas para o método comunicacional. Rio de Janeiro: Vozes. 
* Doutorando no Programa de Pós-Graduação em Estudos de Cultura Contemporânea da Universidade Federal de Mato Grosso (UFMT). Professor do Departamento de Jornalismo da Universidade do Estado de Mato Grosso (UNEMAT). Artigo vinculado ao Projeto de Pesquisa "Comunicação e Cidade: Interfaces Interdisciplinares" (PROPeq/UFMT). prof.gibranluis@gmail.com

** Doutor em Comunicação e Cultura pela Universidade Federal do Rio de Janeiro (UFRJ). Pósdoutor em Comunicação pela Universidade Federal do Ceará (UFC). Professor do Programa de Pós-Graduação em Estudos de Cultura Contemporânea da Universidade Federal de Mato Grosso (UFMT). Artigo vinculado ao Projeto de Pesquisa "Comunicação e Cidade: Interfaces Interdisciplinares" (PROPeq/UFMT).yug@uol.com.br 